\title{
Pulmonary Hemodynamic Response to Exercise in Chronic Thromboembolic Pulmonary Hypertension before and after Pulmonary Endarterectomy
}

\author{
Manuel Jonas Richter ${ }^{a} d$ Natascha Sommer ${ }^{d}$ Henning Gall ${ }^{d}$ \\ Robert Voswinckel ${ }^{\mathrm{e}}$ Werner Seeger ${ }^{\mathrm{d}}$ Eckhard Mayer ${ }^{\mathrm{b}}$ \\ Christoph B. Wiedenroth $^{b}$ Andreas Rieth ${ }^{c}$ Friedrich Grimminger ${ }^{a} d$ \\ Stefan Guth ${ }^{b}$ Hossein A. Ghofrani ${ }^{a, d}$ \\ Departments of a Pneumology, ${ }^{b}$ Thoracic Surgery and ${ }^{\mathrm{C} C}$ Cardiology, Kerckhoff Heart, Rheuma and Thoracic Center, \\ Bad Nauheim, dDepartment of Internal Medicine, Justus Liebig University Giessen, Universities of Giessen and \\ Marburg Lung Center (UGMLC), Member of the German Center for Lung Research (DZL), Giessen, and ${ }^{\mathrm{e}}$ Department \\ of Internal Medicine, Health Center Wetterau, Friedberg, Germany
}

\section{Key Words}

Chronic thromboembolic pulmonary hypertension .

Pulmonary endarterectomy · Exercise $\cdot$ Right heart catheterization

\begin{abstract}
Background: Pulmonary endarterectomy (PEA) is the treatment of choice in surgically accessible chronic thromboembolic pulmonary hypertension (CTEPH). An important predictor of outcome is postsurgical residual pulmonary hypertension. Objective: We aimed to use the hemodynamic response during exercise before PEA as a measurement for the hemodynamic outcome 1 year after PEA. Methods: Between January 2011 and December 2013, 299 patients underwent PEA in our center. A total of 16 patients who were assessed by means of invasive hemodynamic measurements during exercise both at baseline and 1 year after PEA were retrospectively analyzed. Results: Pre-PEA mean pulmonary arterial pressure (mPAP) increased during exercise from 35.8 \pm 7.6 to $53.8 \pm 5.1 \mathrm{~mm} \mathrm{Hg}$, diastolic pulmonary arterial pressure (dPAP) from $21.5 \pm 5.6$ to $30.3 \pm 9.6 \mathrm{~mm} \mathrm{Hg}$, cardiac out-
\end{abstract}

(C) 2015 S. Karger AG, Basel

0025-7931/15/0901-0063\$39.50/0 put (CO) from $4.4 \pm 0.8$ to $6.5 \pm 1.9 \mathrm{l} / \mathrm{min}$ and diastolic pulmonary gradient (DPG) from $14.6 \pm 4.9$ to $20.7 \pm 12.7 \mathrm{~mm} \mathrm{Hg}$. Post-PEA mPAP increased from $23.7 \pm 6.6$ at rest to $43.2 \pm 7.1$ $\mathrm{mm} \mathrm{Hg}$, while $\mathrm{CO}$ increased to a higher extent from $5.1 \pm 0.9$ to $8.4 \pm 1.9 \mathrm{l} / \mathrm{min}$. There were significant correlations between pre-PEA DPG/CO and dPAP/CO slopes with the pulmonary vascular resistance (Spearman $r=0.578, p=0.019$, and $r=0.547, p=0.028$ ) and mPAP at rest after PEA (Spearman $r=0.581, p=0.018$, and $r=0.546, p=0.028$ ). Conclusions: In CTEPH, the presurgical dynamic DPG/CO and dPAP/ $\mathrm{CO}$ slopes during submaximal exercise are associated with the hemodynamic outcome 1 year after PEA.

(c) 2015 S. Karger AG, Basel

\section{Introduction}

Chronic thromboembolic pulmonary hypertension (CTEPH) is caused by unresolved pulmonary vascular obstruction following acute pulmonary embolism. Untreated, the disease may progress towards increased pulmonary pressures, progressive right ventricular load and finally

\section{KARGER 125}

E-Mail karger@karger.com www.karger.com/res
Manuel Jonas Richter

Department of Pneumology, Kerckhoff Heart, Rheuma and Thoracic Center Benekestrasse 2-6

DE-61231 Bad Nauheim (Germany)

E-Mail ma.richter@ kerckhoff-klinik.de 
failure $[1,2]$. Initially, an increase in mean pulmonary arterial pressure (mPAP) and pulmonary vascular resistance (PVR) is caused predominantly by the mechanical obstruction of the proximal pulmonary arteries; the further progression of the disease is mainly thought to be induced by secondary small-vessel arteriopathy in the nonobstructed, hyperperfused areas $[1,2]$. The right ventricle (RV) adapts to the increased afterload either by hypertrophy or maladaptive dilatation [3], while the patient outcome is mostly determined by the response of the RV to strain [4, 5]. Pulmonary endarterectomy (PEA) has proven to substantially enhance pulmonary hemodynamics, exercise capacity [6-9] and survival [10]. However, predicting those patients with favorable long-term results remains challenging. Residual pulmonary hypertension (PH) after surgery has been identified as the main determinant for longterm outcome in terms of survival [11] or functional capacity [12]. Preoperative predictors of early postoperative outcome in terms of decreased PVR $48 \mathrm{~h}$ after PEA are mPAP [13], serum creatinine level, the number of involved segments, PVR and gender [14]. Parameters for risk stratification for PEA include preoperative forced expiratory volume in $1 \mathrm{~s}$ and cardiac index (CI) as well as preoperative arterial oxygenation [13]. However, predictors for longterm hemodynamic response are less well defined. In most cases, the residual PH after PEA results from a combination of concomitant small-vessel disease, incomplete removal of obstructions and a varying degree of right ventricular recovery after surgery [15]. Thus, the optimal characterization of the contribution of large- and small-vessel disease in CTEPH is important regarding the indication and outcome after PEA [16]. Along these lines, the echocardiographic parameter 'notch ratio', which describes the pulmonary arterial blood flow pattern, was shown to predict residual PH 3 months after PEA [17], whereas resting hemodynamic parameters before PEA did not correlate with hemodynamic parameters after PEA [18]. In idiopathic pulmonary arterial hypertension $(\mathrm{PAH})$, recently published data indicate a superiority of exercise pulmonary measurements as prognostic factors [19]. Moreover, in a small cohort of CTEPH patients with persistent dyspnea after PEA but normal pulmonary hemodynamics at rest, the diminished pulmonary arterial compliance (Cpa) during exercise was a strong predictor of limited functional capacity [20]. Furthermore, Blumberg et al. [21] showed that in a heterogeneous group of PAH and inoperable CTEPH patients the relationship of MPAP to cardiac output (CO) during exercise served as a predictor of survival. In healthy volunteers, exercise leads to an increased $\mathrm{CO}$ and mean left atrial pressure, each of which results in a slightly increased mPAP with a flat slope of $\mathrm{mPAP} / \mathrm{CO}$ between 0.5 and $3.0 \mathrm{~mm} \mathrm{Hg} / \mathrm{l} / \mathrm{min}$ [22]. In contrast, $\mathrm{PAH}$ was characterized by a reduced $\mathrm{CO}$ at rest with inadequate response to exercise and a steep mPAP/CO slope [22-24].

We thus hypothesized that exercise hemodynamics with assessment of pressure/flow slopes in surgically accessible CTEPH patients may determine hemodynamic improvements after PEA.

\section{Methods}

\section{Patients}

We retrospectively we evaluated 299 consecutive patients diagnosed with CTEPH, referred to the Department of Thoracic Surgery, Kerckhoff Clinic, Bad Nauheim, Germany. Between January 2011 and December 2013, 299 PEA were performed. In 114 of these patients, right heart catheterization (RHC) before PEA was performed in-house, and 62 patients returned for the 1-year postPEA follow-up undergoing RHC (fig. 1). According to internal safety standards, only patients with compensated right heart function with an $\mathrm{mPAP}<50 \mathrm{~mm} \mathrm{Hg}$ and a CI $>1.5 \mathrm{l} / \mathrm{min} / \mathrm{m}^{2}$ at rest were selected for exercise RHC. We here describe the results of 16 patients who underwent exercise RHC in the Kerckhoff Clinic before and 1 year after PEA under the same conditions by the same investigator; complete data were available from all patients. Residual $\mathrm{PH}$ 1 year after PEA was defined by an mPAP > $25 \mathrm{~mm} \mathrm{Hg}$ and PVR $>240$ dyne $\cdot \mathrm{s} / \mathrm{cm}^{5}$ at rest [12].

Data collection and analyses were approved, and the need to obtain written informed consent from each patient was waived by the Ethics Committee of the Faculty of Medicine at the University of Giessen (approval No. 67/14).

All CTEPH patients were diagnosed according to current guidelines [25]. Operability assessment was done by a multidisciplinary board consisting of PEA surgeons, radiologists and pulmonary physicians. All patients performed a 6-min walk test, cardiopulmonary exercise testing, echocardiography and measurement of N-terminal pro-brain natriuretic peptide levels (NT-proBNP). At inclusion, all patients received oral anticoagulants for at least 3 months. Exclusion criteria for the study were defined by concomitant left-sided heart disease. All patients included underwent PEA according to the protocol of the Kerckhoff Clinic [26]. The CTEPH type was classified by the surgical specimen as reported previously [27].

\section{Right Heart Catheterization}

All included patients underwent RHC by insertion of a SwanGanz catheter under local anesthesia. Pressure values at rest were continuously assessed [systolic pulmonary arterial pressure (sPAP); diastolic pulmonary arterial pressure (dPAP); mPAP; right atrial pressure, and pulmonary arterial wedge pressure (PAWP)], while the $\mathrm{CO}$ was measured by the thermodilution technique, averaging 3 of 5 output determinations. Baseline parameters were assessed 30 min after insertion of the catheter. PVR and $\mathrm{CI}$ were calculated as described previously $[\mathrm{PVR}=(\mathrm{mPAP}-$ $\mathrm{PAWP}) / \mathrm{CO} ; \mathrm{CI}=(\mathrm{CO} /$ body surface area $)$ ] [25]. Exercise was performed on a cycle ergometer in supine position with a constant external workload of 25,50 or $75 \mathrm{~W}$. The workload was judged by the operator clinically and according to the workload achieved 


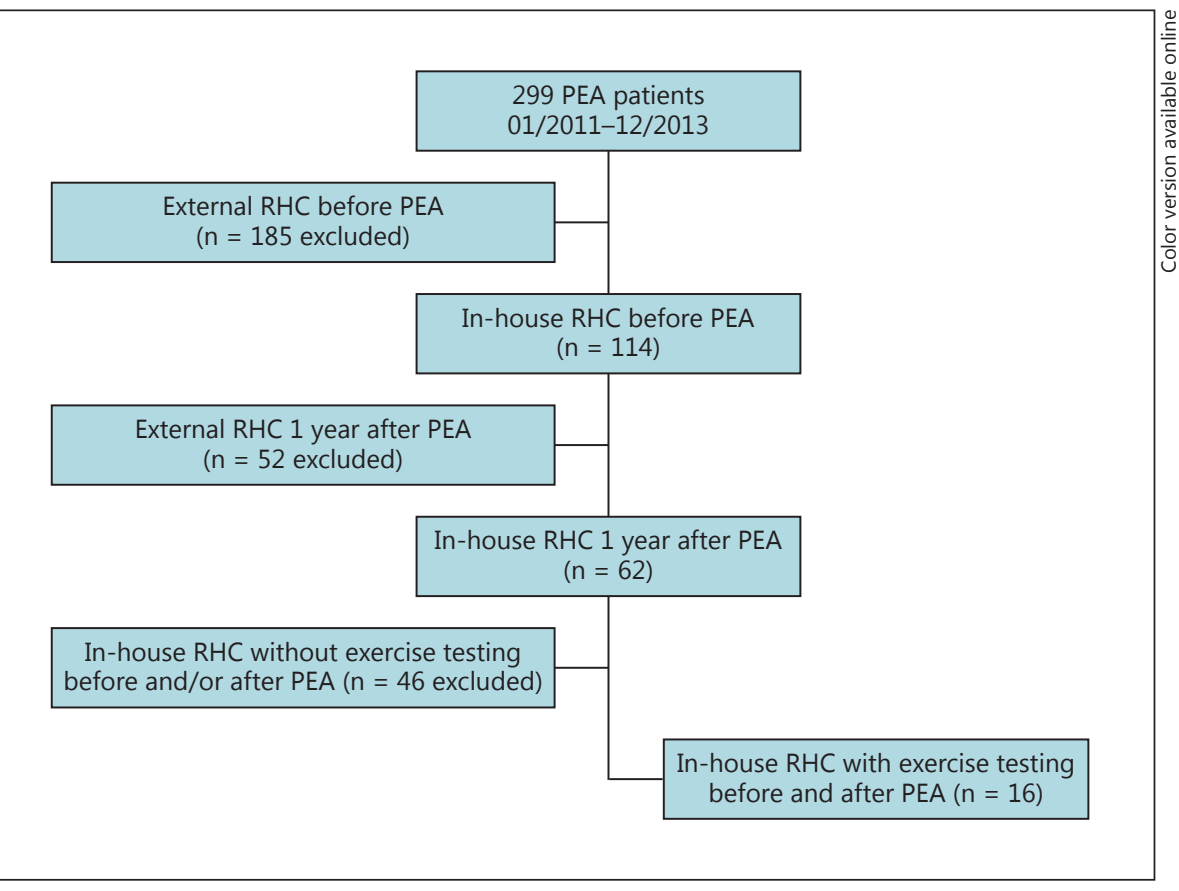

Fig. 1. Flowchart of the patient selection.

during cardiopulmonary exercise testing, to allow the patient to exercise in a steady-state condition for at least $8 \mathrm{~min}$, as reported previously $[21,28]$. The anterior axillary line served as the zero reference in all supine measurements [28]. During constant workload, 3 min after the start of exercise, the measurements of exercise hemodynamic parameters were performed, with a total duration of approximately 5-7 min [19]. Pulmonary pressures were averaged over several respiratory cycles during the constant workload under exercise [29]. Mixed venous oxygen saturation $\left(\mathrm{SvO}_{2}\right)$ was obtained via blood gas analysis at rest and at the end of exercise. The following hemodynamic parameters were calculated: transpulmonary gradient $(\mathrm{TPG})=\mathrm{mPAP}-\mathrm{PAWP}$, diastolic pulmonary gradient $(\mathrm{DPG})=\mathrm{dPAP}-\mathrm{PAWP}$, and the slopes of hemodynamic parameters related to $\mathrm{CO}$ as described previously $(\mathrm{mPAP} / \mathrm{CO}$, $\mathrm{PVR} / \mathrm{CO}, \mathrm{sPAP} / \mathrm{CO}, \mathrm{dPAP} / \mathrm{CO}, \mathrm{PAWP} / \mathrm{CO}, \mathrm{SvO}_{2} / \mathrm{CO}, \mathrm{TPG} / \mathrm{CO}$ and DPG/CO) $[22,30]$. Adjustment of these pressure-flow curves can be done with a mathematical model, but in recent studies, the slopes were best described by a linear approximation $[22,30]$.

\section{Cardiopulmonary Exercise Testing}

All patients performed a symptom-limited incremental cardiopulmonary exercise testing (Masterscreen ${ }^{\circledR}$, Carefusion ${ }^{\circledR}$ ) 1 day before RHC according to current recommendations using a ramp protocol with an incremental rate of $5-15 \mathrm{~W} / \mathrm{min}$ judged by the operator [31]. Patients were seated in semi-supine position, wearing a face mask until the end of exercise. The latter was terminated when the predefined endpoints were reached [31] or at any time the patient felt he/she was unable to continue due to symptoms.

The 6-Min Walk Test

The 6-min walk test was performed according to current recommendations and recorded as the distance covered in meters (6MWD) [32]. All patients were instructed to walk at their own pace along a 30-meter corridor while standard phrases as stated in the American Thoracic Society protocol were communicated [32].

\section{Echocardiography}

Right heart echocardiography was performed according to current recommendations with the assessment of pulmonary artery systolic pressure (PASP) and tricuspid annular plane systolic excursion (TAPSE) [33].

\section{Statistical Analysis}

Data are expressed as means \pm SD or means \pm SEM. Parameters before PEA and 1 year after PEA were compared with the paired $t$ test for normally distributed parameters or the Wilcoxon signedrank test for nonnormally distributed parameters. The two-tailed $t$ test or Mann-Whitney $U$ test was used to test for differences between residual and nonresidual PH. Spearman's rank correlation test was used to determine whether hemodynamic slopes before PEA were associated with parameters after PEA. $p<0.05$ was considered statistically significant for comparison between groups. Statistical analysis was performed using SPSS, version 21.0 (IBM, Armonk, N.Y., USA).

\section{Results}

\section{Pre-PEA Patient Characteristics and Pulmonary Hemodynamics at Rest}

A total of 16 patients with a mean age of $60.8 \pm 14.8$ years and a mean BMI of $24.7 \pm 4.6$ were included. At baseline, 12 patients $(71 \%)$ were in WHO functional class III and 1 patient was receiving specific PAH therapy as 
Table 1. Baseline characteristics

\begin{tabular}{lcc}
\hline & Before PEA & $\begin{array}{l}\text { One year after } \\
\text { PEA }\end{array}$ \\
\hline Patients, $\mathrm{n}$ & 16 & \\
Male/female & $10 / 6$ & \\
Age, years & $60.8 \pm 14.8$ & $61.9 \pm 14.4$ \\
BMI & $24.7 \pm 4.6$ & $25.9 \pm 5.2^{* *}$ \\
WHO functional class, $\mathrm{n}(\%)$ & & \\
I & - & $4(23)$ \\
II & $3(18)$ & $12(71)$ \\
$\quad$ III & $12(71)$ & $1(6)$ \\
IV & $2(11)$ & - \\
NT-proBNP, pg/ml & $1,419.8 \pm 1,093.1$ & $413.7 \pm 369.7^{* *}$ \\
Peak VO ${ }_{2}, \mathrm{ml} \cdot \mathrm{kg}^{-1} \cdot \mathrm{min}^{-1}$ & $13.6 \pm 5.9$ & $17.9 \pm 4.6^{* *}$ \\
TAPSE, mm & $17.7 \pm 5.5$ & $18.8 \pm 3$ \\
PASP, mm Hg & $81.7 \pm 19.8$ & $43.4 \pm 8.7^{\#}$ \\
6MWD, m & $345.6 \pm 117.5$ & $485.6 \pm 105.9^{\#}$ \\
Targeted PAH therapy, $\mathrm{n}(\%)$ & $1(6)$ & - \\
Phosphodiesterase type 5 in- & & \\
$\quad$ hibitors, $\mathrm{n}(\%)$ & $1(6)$ & - \\
Therapy naive, $\mathrm{n}(\%)$ & $15(94)$ & - \\
Jamieson type, $\mathrm{n}(\%)$ & & - \\
I & $2(13)$ & \\
II & $9(56)$ & \\
III & $5(31)$ & \\
\hline
\end{tabular}

Values represent mean \pm SD unless indicated otherwise. ${ }^{\#} \mathrm{p}<$ 0.001 (Wilcoxon signed-rank test), ${ }^{* *} \mathrm{p}<0.01$ (* $=$ paired t test) versus baseline. $\mathrm{VO}_{2}=$ Oxygen uptake; $\mathrm{BMI}=$ body mass index.

shown in table 1. Increased NT-proBNP levels were noticed while the exercise capacity was substantially reduced. Right heart echocardiography showed a decreased TAPSE and an elevated PASP (table 1).

Pre-PEA patients exhibited a precapillary $\mathrm{PH}$ with an elevated mPAP, TPG, DPG and PVR, a normal PAWP and an impaired CO, while the $\mathrm{SvO}_{2}$ was reduced (table 2).

\section{Pulmonary Hemodynamic Profile during Exercise before PEA}

During exercise, the heart rate significantly increased while $\mathrm{SpO}_{2}$ and $\mathrm{SvO}_{2}$ decreased. The pulmonary hemodynamic profile showed an increase in mPAP from 35.8 \pm 7.6 to $53.8 \pm 5.1 \mathrm{~mm} \mathrm{Hg}$, while the CO increased only slightly from $4.4 \pm 0.8$ to $6.5 \pm 1.9 \mathrm{l} / \mathrm{min}$, resulting in a steep $\mathrm{mPAP} / \mathrm{CO}$ slope of $13.3 \pm 10.8 \mathrm{~mm} \mathrm{Hg} / \mathrm{l} / \mathrm{min}$ (fig. 2a). In parallel, sPAP, dPAP, PAWP, right atrial pressure, TPG and DPG increased significantly during exercise, while the change in PVR during exercise was minimal. The relationship between $\mathrm{CO}$ and the hemodynam- ic parameters is displayed in table 3. Steep slopes of sPAP/ CO, dPAP/CO, PVR/CO, DPG/CO, PAWP/CO and TPG/CO were observed (table 3; fig. 2).

\section{One Year after PEA}

One year after PEA, patients presented with a slightly higher BMI and mostly in WHO functional class I (23\%) and II (71\%), respectively. Significant improvements in the exercise capacity (6MWD, peak $\left.\mathrm{VO}_{2}\right)$, PASP and reduction of NT-proBNP levels were evident in comparison with pre-PEA values (table 1).

mPAP, sPAP, dPAP and TPG after PEA were lower during rest and exercise with concomitant improvement of $\mathrm{CO}$ and $\mathrm{SvO}_{2}$ (table 2), while the absolute changes during exercise were not significantly different in comparison to pre-PEA (table 3). In contrast, the CO during exercise increased after PEA to a significantly higher extent than pre-PEA (table 3 ). Therefore, the post-PEA slopes of sPAP/CO, mPAP/CO and TPG/CO were flattened compared to before PEA (fig. 2). However, the slopes of dPAP/ $\mathrm{CO}, \mathrm{PAWP} / \mathrm{CO}, \mathrm{PVR} / \mathrm{CO}, \mathrm{SvO}_{2} / \mathrm{CO}$ and DPG/CO were not significantly different (table 3 ; fig. 2).

A residual $\mathrm{PH}$ was observed in 7 patients, while significantly impaired pulmonary hemodynamics at rest and during exercise in comparison with nonresidual $\mathrm{PH}$ were observed. Numerically, albeit not significant, the slopes of mPAP/CO, dPAP/CO and TPG/CO showed a less steep pattern in nonresidual $\mathrm{PH}$ (table 4).

\section{Association of Pre-PEA Hemodynamics with}

Hemodynamic Outcome One Year after PEA

With the exception of TPG, resting pressure values before PEA were not significantly associated with hemodynamics after PEA (table 5).

The $\mathrm{dPAP} / \mathrm{CO}$ and DPG/CO slopes before PEA were significantly associated with PVR at rest after PEA and $\mathrm{mPAP}$ at rest after PEA, while $\mathrm{mPAP} / \mathrm{CO}, \mathrm{sPAP} / \mathrm{CO}$ and TPG/CO failed to correlate with parameters after PEA (table 5; fig. 3).

Additionally, mPAP/CO was significantly associated with NT-proBNP after PEA (Spearman $\mathrm{r}=0.59, \mathrm{p}=0.03$ ), and sPAP/CO was correlated with $6 \mathrm{MWD}$ after PEA (Spearman $\mathrm{r}=-0.7, \mathrm{p}=0.02$ ).

\section{Discussion}

In the current study, we could show for the first time that the hemodynamic response to exercise before PEA is associated with hemodynamic outcome after PEA. The 
Table 2. Hemodynamic parameters at rest and during exercise

\begin{tabular}{|c|c|c|c|c|}
\hline & \multicolumn{2}{|l|}{ Before PEA } & \multicolumn{2}{|c|}{ One year after PEA } \\
\hline & rest & exercise & rest & exercise \\
\hline sPAP, mm Hg & $64.5 \pm 13.3$ & $94.2 \pm 8.5^{\#}$ & $39 \pm 10.8^{*}$ & $70.9 \pm 15.5^{*, \#}$ \\
\hline mPAP, mm Hg & $35.8 \pm 7.6$ & $53.8 \pm 5.1^{\#}$ & $23.7 \pm 6.6^{*}$ & $43.2 \pm 7.1^{*, \#}$ \\
\hline dPAP, mm Hg & $21.5 \pm 5.6$ & $30.3 \pm 9.6^{\#}$ & $14.1 \pm 6.4^{*}$ & $23.7 \pm 5.4^{* *, \#}$ \\
\hline $\mathrm{RA}, \mathrm{mm} \mathrm{Hg}$ & $5.9 \pm 2.1$ & $13 \pm 3.4^{\#}$ & $5.8 \pm 2.8$ & $14.7 \pm 4.6^{\#}$ \\
\hline PAWP, mm Hg & $7.3 \pm 2.9$ & $11.8 \pm 4.8^{\#}$ & $10.4 \pm 3.6^{* * *}$ & $19.1 \pm 6.1^{* *, \#}$ \\
\hline $\mathrm{TPG}, \mathrm{mm} \mathrm{Hg}$ & $28.9 \pm 6.8$ & $44.3 \pm 8.8^{\#}$ & $13.3 \pm 6.9^{*}$ & $24.1 \pm 7.9^{*, \#}$ \\
\hline $\mathrm{DPG}, \mathrm{mm} \mathrm{Hg}$ & $14.6 \pm 4.9$ & $20.7 \pm 12.7^{\dagger}$ & $3.6 \pm 6.9^{\dagger \dagger}$ & $4.6 \pm 6.8$ \\
\hline PVR, dyne.s/ $\mathrm{cm}^{5}$ & $522.6 \pm 151.2$ & $529.8 \pm 161.5$ & $213 \pm 117.3^{*}$ & $246.2 \pm 113.6^{*}$ \\
\hline $\mathrm{CO}, 1 / \mathrm{min}$ & $4.4 \pm 0.8$ & $6.5 \pm 1.9^{\#}$ & $5.1 \pm 0.9^{* * *}$ & $8.4 \pm 1.9^{*, \#}$ \\
\hline $\mathrm{CI}, 1 / \mathrm{min} / \mathrm{m}^{2}$ & $2.4 \pm 0.5$ & $3.5 \pm 1.2^{\#}$ & $2.6 \pm 0.5$ & $4.7 \pm 1.9^{* *, \#}$ \\
\hline $\mathrm{SvO}_{2}, \%$ & $66.6 \pm 6.2$ & $41.7 \pm 14.2^{\#}$ & $72.8 \pm 5.4^{*}$ & $39.5 \pm 5.9^{\#}$ \\
\hline $\mathrm{HR}$, beats/min & $74 \pm 15$ & $96 \pm 15^{\#}$ & $75.7 \pm 10.6$ & $104.3 \pm 15.7^{* * *, \#}$ \\
\hline $\mathrm{SpO}_{2}, \%$ & $93.9 \pm 3.1$ & $88.5 \pm 4.8^{\#}$ & $96.1 \pm 2.5^{* * *}$ & $92.3 \pm 3.1^{* * *, \# \#}$ \\
\hline Workload, W & - & $32 \pm 16.4$ & - & $44 \pm 20.2^{\dagger \dagger \dagger}$ \\
\hline
\end{tabular}

Values represent mean $\pm \mathrm{SD} .{ }^{*} \mathrm{p}<0.001,{ }^{* *} \mathrm{p}<0.01,{ }^{* * *} \mathrm{p}<0.05$ versus before PEA, ${ }^{*} \mathrm{p}<0.001,{ }^{\# \#} \mathrm{p}<0.01$ versus rest $\left({ }^{*}, \#=\right.$ paired $t$ test $),{ }^{\dagger} \mathrm{p}<0.01$ versus rest, ${ }^{\dagger \dagger} \mathrm{p}<0.001,{ }^{\dagger \dagger \dagger} \mathrm{p}<0.01$ versus before PEA $\left({ }^{\dagger}=\mathrm{W}\right.$ ilcoxon signed-rank test). $\mathrm{RA}=$ Right atrium; $\mathrm{HR}=$ heart rate; $\mathrm{SpO}_{2}=$ blood oxygen saturation.

Table 3. Hemodynamic parameters in absolute change $(\Delta)$ from rest to exercise and related to CO (l/min)

\begin{tabular}{lccccc}
\hline & \multicolumn{2}{l}{ Before PEA } & & \multicolumn{2}{l}{ One year after PEA } \\
\cline { 2 - 3 } \cline { 5 - 6 } & $\Delta$ & slope $(\mathrm{CO})$ & $\Delta$ & slope $(\mathrm{CO})$ \\
\hline sPAP, mm Hg & $29.7 \pm 12.1$ & $19.9 \pm 12.6$ & & $31.9 \pm 8.7$ & $12.5 \pm 8.8^{* * *}$ \\
$\mathrm{mPAP}, \mathrm{mm} \mathrm{Hg}$ & $18.1 \pm 7$ & $13.3 \pm 10.8$ & & $19.4 \pm 4.6$ & $6.4 \pm 2.6^{\dagger \dagger}$ \\
$\mathrm{dPAP}, \mathrm{mm} \mathrm{Hg}$ & $8.8 \pm 8$ & $7.7 \pm 13.2$ & & $9.6 \pm 4.9$ & $3.4 \pm 2.5$ \\
$\mathrm{PAWP}, \mathrm{mm} \mathrm{Hg}$ & $5.1 \pm 4.9$ & $4.4 \pm 5.1$ & & $8.7 \pm 4.6^{* * *}$ & $3.5 \pm 2.7$ \\
$\mathrm{RA}, \mathrm{mm} \mathrm{Hg}$ & $7.1 \pm 2.9$ & $5.9 \pm 6.3$ & & $9 \pm 3.6^{* * *}$ & $5.8 \pm 4.5$ \\
$\mathrm{PVR}, \mathrm{dyne} \cdot \mathrm{s} / \mathrm{cm}^{5}$ & $26.1 \pm 66.2$ & $16.4 \pm 122.3$ & & $25.8 \pm 62.5$ & $11.5 \pm 36.7$ \\
$\mathrm{SvO}, \%$ & $-27.9 \pm 14.3$ & $-23.4 \pm 20.6$ & & $-33.4 \pm 5.9$ & $-25.1 \pm 17.5$ \\
$\mathrm{TPG}, \mathrm{mm} \mathrm{Hg}$ & $15.4 \pm 9.5$ & $19.7 \pm 20.6$ & & $10.8 \pm 5.5$ & $6.6 \pm 4.9^{* * *}$ \\
$\mathrm{DPG}, \mathrm{mm} \mathrm{Hg}$ & $6.1 \pm 11$ & $5.1 \pm 14.3$ & & $0.9 \pm 5.4$ & $0.6 \pm 3.4$ \\
$\mathrm{CO}, \mathrm{l} / \mathrm{min}$ & $2.1 \pm 1.7$ & - & $3.3 \pm 1.5^{* * *}$ & - \\
\hline
\end{tabular}

Values represent mean $\pm \mathrm{SD}$. ${ }^{* * *} \mathrm{p}<0.05$ versus before PEA (paired $\mathrm{t}$ test); ${ }^{\dagger \dagger \dagger} \mathrm{p}<0.01$ versus before PEA (Wilcoxon signed-rank test). $\mathrm{RA}=$ Right atrium.

novel findings of the present study show that exercisedependent pressure-flow relationships before PEA were improved 1 year after PEA, indicating an enhanced capacity of the pulmonary vascular system after PEA, and that they were better correlated to the hemodynamic outcome 1 year after PEA than baseline resting hemodynamic parameters. To the best of our knowledge, this is the first study that evaluated submaximal exercise hemodynamic parameters in a selected cohort of CTEPH patients and demonstrated their impact on the hemodynamic outcome after PEA.

The investigated study population was comprised of patients diagnosed with surgically accessible CTEPH (PH group 4 according to the WHO classification) and severe- 

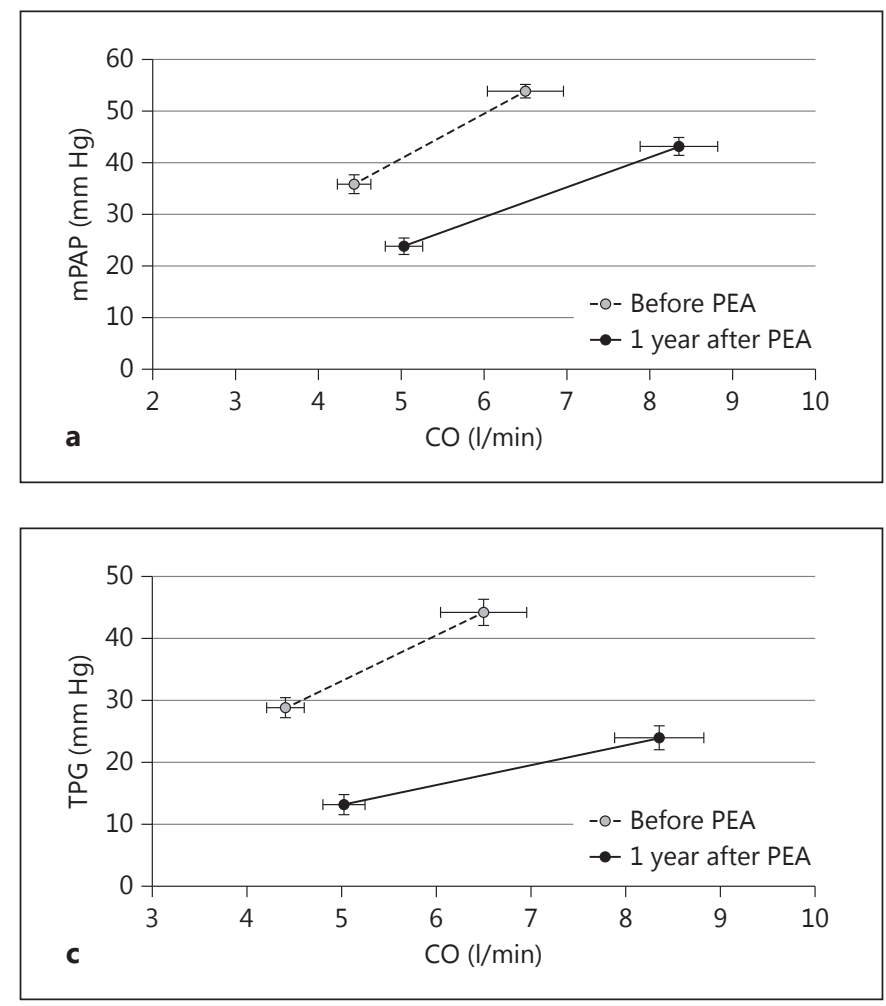

Fig. 2. Linear pressure-flow relationships before and after PEA during constant exercise. a mPAP/CO slope. b dPAP/CO slope. c TPG/CO slope. d DPG/CO slope. e PAWP/CO slope. Values represent mean $\pm \mathrm{SEM}$.

ly impaired exercise capacity characterized by low $6 \mathrm{MWD}$, low peak $\mathrm{VO}_{2}$, and mostly being in WHO functional class III. In comparison to previous studies, our patient group showed a similar hemodynamic profile at rest characterized by an impairment of the RV function as well as high PVR and pressures before PEA [6, 34-37]. As expected, the mPAP, PVR and CO at rest after PEA in our study improved significantly; however, 7 patients exhibited residual $\mathrm{PH}$ in our selected cohort. Our findings are in accordance with previously published data showing substantial improvement of the pulmonary hemodynamics 1 year after PEA. However, the individual outcome differed and approximately $10-24 \%$ of patients re-
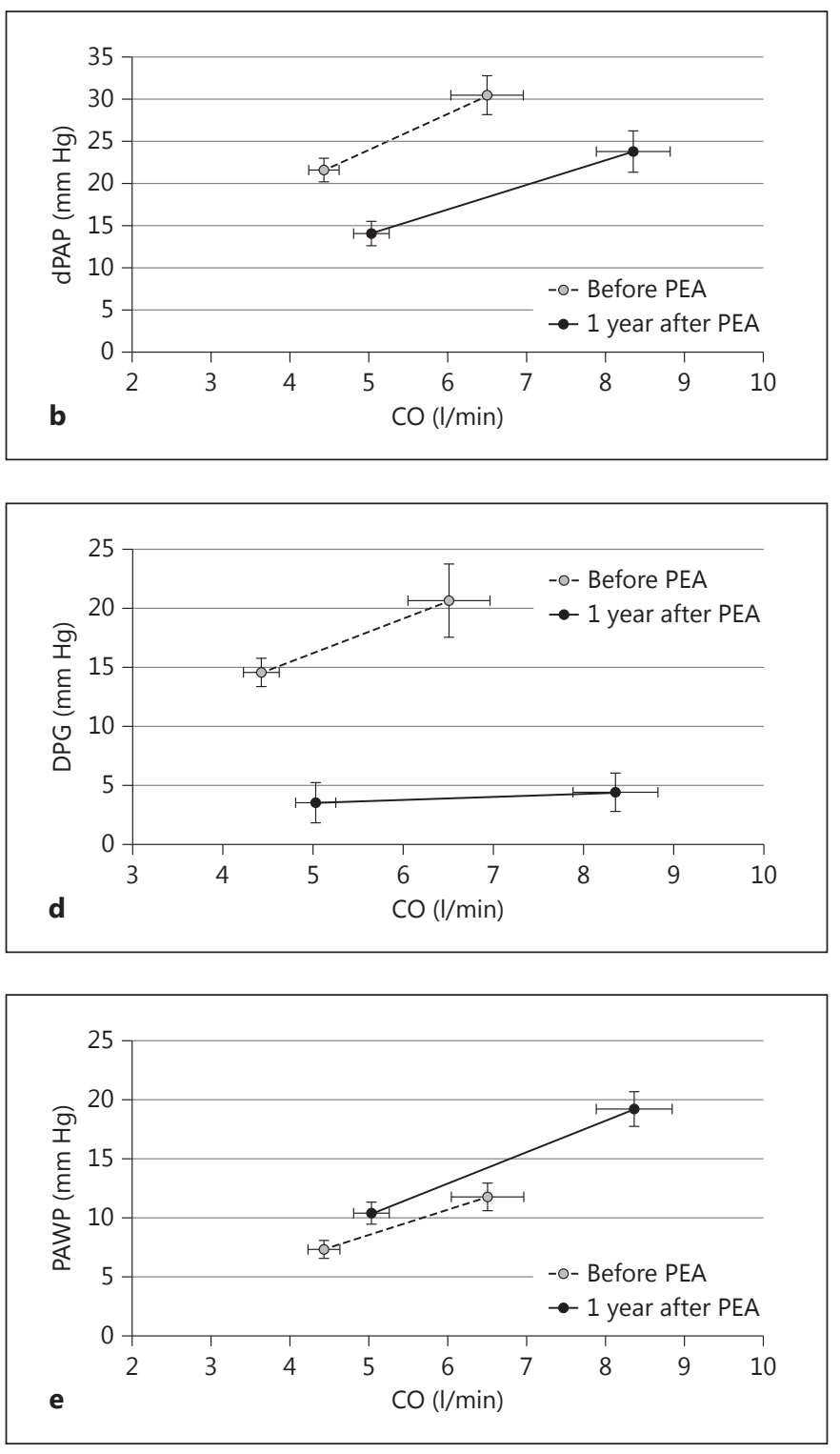

main symptomatic after PEA $[9,38]$ and up to $35 \%$ presented with residual $\mathrm{PH}[12,36,39]$.

For example, cardiac magnetic resonance imaging studies under strain indicated that in CTEPH, exercise was limited by an RV impairment and increased PVR, which failed to be reversible after PEA in some patients [40]. Taking into account that PEA is a surgery with considerable risk, patients that most likely benefit from the surgery in the long term have to be selected carefully. Persistence or recurrence of $\mathrm{PH}$ is regarded as main prognostic factor for long-term survival [11] or functional capacity [12]. Several mechanisms such as incomplete removal of obstructions and irreversible small-vessel arteriopathy 
Table 4. Parameters according to residual PH after 1 year

\begin{tabular}{|c|c|c|c|c|}
\hline & \multicolumn{2}{|c|}{ Nonresidual PH $(\mathrm{n}=9,56 \%)$} & \multicolumn{2}{|c|}{ Residual PH (n = 7, 44\%) } \\
\hline & rest & exercise & rest & exercise \\
\hline mPAP, mm Hg & $18.7 \pm 2.6^{*}$ & $30.3 \pm 3.1^{*}$ & $30.3 \pm 3.1$ & $49.6 \pm 4.5$ \\
\hline $\mathrm{dPAP}, \mathrm{mm} \mathrm{Hg}$ & $9.6 \pm 3.3^{*}$ & $20.2 \pm 3.6^{*}$ & $19.9 \pm 4.1$ & $28.1 \pm 3.9$ \\
\hline PAWP, mm Hg & $9.7 \pm 3.7$ & $19.3 \pm 6.9$ & $11.4 \pm 3.4$ & $18.9 \pm 5.2$ \\
\hline $\mathrm{TPG}, \mathrm{mm} \mathrm{Hg}$ & $9 \pm 4.1^{*}$ & $18.9 \pm 6.2^{*}$ & $18.8 \pm 6$ & $30.7 \pm 3.4$ \\
\hline DPG, $\mathrm{mm} \mathrm{Hg}$ & $2.5 \pm 2.8$ & $3.0 \pm 4.7^{\# \# \#}$ & $7.8 \pm 4.1$ & $8.4 \pm 6.5$ \\
\hline PVR, dyne.s $/ \mathrm{cm}^{5}$ & $130.6 \pm 50.3^{\#}$ & $161.1 \pm 35.2^{*}$ & $319 \pm 88.1$ & $365.4 \pm 56.7$ \\
\hline $\mathrm{CO}, 1 / \mathrm{min}$ & $5.3 \pm 0.9$ & $9.1 \pm 1.9$ & $4.6 \pm 0.8$ & $7.4 \pm 1.5$ \\
\hline $\mathrm{HR}$, beats/min & $76 \pm 11$ & $105 \pm 15$ & $75 \pm 10$ & $103 \pm 17$ \\
\hline $\mathrm{mPAP} / \mathrm{CO}, \mathrm{mm} \mathrm{Hg} / \mathrm{l} / \mathrm{min}$ & $5.8 \pm 2.5$ & & $7.2 \pm 2.7$ & \\
\hline $\mathrm{dPAP} / \mathrm{CO}, \mathrm{mm} \mathrm{Hg} / \mathrm{l} / \mathrm{min}$ & $3.2 \pm 1.7$ & & $3.7 \pm 3.3$ & \\
\hline $\mathrm{TPG} / \mathrm{CO}, \mathrm{mm} \mathrm{Hg} / \mathrm{l} / \mathrm{min}$ & $4.8 \pm 3.8$ & & $9.1 \pm 5.4$ & \\
\hline $\mathrm{DPG} / \mathrm{CO}, \mathrm{mm} \mathrm{Hg} / \mathrm{l} / \mathrm{min}$ & $0.6 \pm 2.5$ & & $0.5 \pm 4.6$ & \\
\hline NT-proBNP, pg/ml & $159.1 \pm 122.5^{\# \#}$ & & $753.2 \pm 303.9$ & \\
\hline $6 \mathrm{MWD}, \mathrm{m}$ & $511 \pm 111.1$ & & $454 \pm 94$ & \\
\hline \multicolumn{5}{|l|}{ Jamieson type, n (\%) } \\
\hline I & $2(22)$ & & & \\
\hline II & $5(56)$ & & $4(57)$ & \\
\hline III & $2(22)$ & & $3(43)$ & \\
\hline
\end{tabular}

Values represent mean \pm SD unless otherwise indicated. ${ }^{*} \mathrm{p}<0.001 ;{ }^{\# \#} \mathrm{p}<0.01 ;{ }^{* *} \mathrm{p}<0.01 ;{ }^{\# \#} \mathrm{p}<0.05$; ${ }^{* * *} \mathrm{p}<0.05$ versus residual PH $\left(*=\right.$ two-tailed $\mathrm{t}$ test, ${ }^{*}=$ Mann-Whitney U test).

Table 5. Correlations between hemodynamic parameters before PEA with PVR and mPAP at rest 1 year after PEA using Spearman's rank correlation test

\begin{tabular}{|c|c|c|c|c|}
\hline \multirow[t]{2}{*}{ Parameters before PEA } & \multicolumn{2}{|c|}{$\begin{array}{l}\text { PVR at rest }\left(\text { dyne.s } / \mathrm{cm}^{5}\right) \\
\text { one year after PEA }\end{array}$} & \multicolumn{2}{|c|}{$\begin{array}{l}\mathrm{mPAP} \text { at rest }(\mathrm{mm} \mathrm{Hg}) \\
\text { one year after PEA }\end{array}$} \\
\hline & $\mathrm{r}$ & $\mathrm{p}$ value & $\mathrm{r}$ & $\mathrm{p}$ value \\
\hline mPAP rest (mm Hg) & 0.29 & 0.28 & 0.48 & 0.055 \\
\hline sPAP rest $(\mathrm{mm} \mathrm{Hg})$ & 0.3 & 0.25 & 0.51 & 0.045 \\
\hline dPAP rest (mm Hg) & 0.22 & 0.42 & 0.32 & 0.22 \\
\hline CO rest $(1 / \mathrm{min})$ & -0.4 & 0.11 & -0.15 & 0.57 \\
\hline CI rest $\left(1 / \mathrm{min} / \mathrm{m}^{2}\right)$ & -0.14 & 0.62 & 0.05 & 0.85 \\
\hline TPG rest (mm Hg) & 0.49 & 0.057 & 0.57 & 0.02 \\
\hline $\mathrm{DPG}$ rest $(\mathrm{mm} \mathrm{Hg})$ & 0.38 & 0.14 & 0.36 & 0.18 \\
\hline PVR at rest $\left(\right.$ dyne $\left.\cdot s / \mathrm{cm}^{5}\right)$ & 0.41 & 0.13 & 0.44 & 0.9 \\
\hline $\mathrm{mPAP} / \mathrm{CO}(\mathrm{mm} \mathrm{Hg} / \mathrm{l} / \mathrm{min})$ & 0.39 & 0.14 & 0.29 & 0.27 \\
\hline $\mathrm{sPAP} / \mathrm{CO}(\mathrm{mm} \mathrm{Hg} / \mathrm{l} / \mathrm{min})$ & 0.22 & 0.41 & 0.25 & 0.35 \\
\hline $\mathrm{dPAP} / \mathrm{CO}(\mathrm{mm} \mathrm{Hg} / \mathrm{l} / \mathrm{min})$ & 0.547 & 0.028 & 0.546 & 0.029 \\
\hline TPG/CO (mm Hg/l/min) & 0.3 & 0.25 & 0.31 & 0.25 \\
\hline DPG/CO (mm Hg/l/min) & 0.578 & 0.019 & 0.581 & 0.018 \\
\hline
\end{tabular}

Figures in bold are highlighting significant values $(\mathrm{p}<0.05)$. 

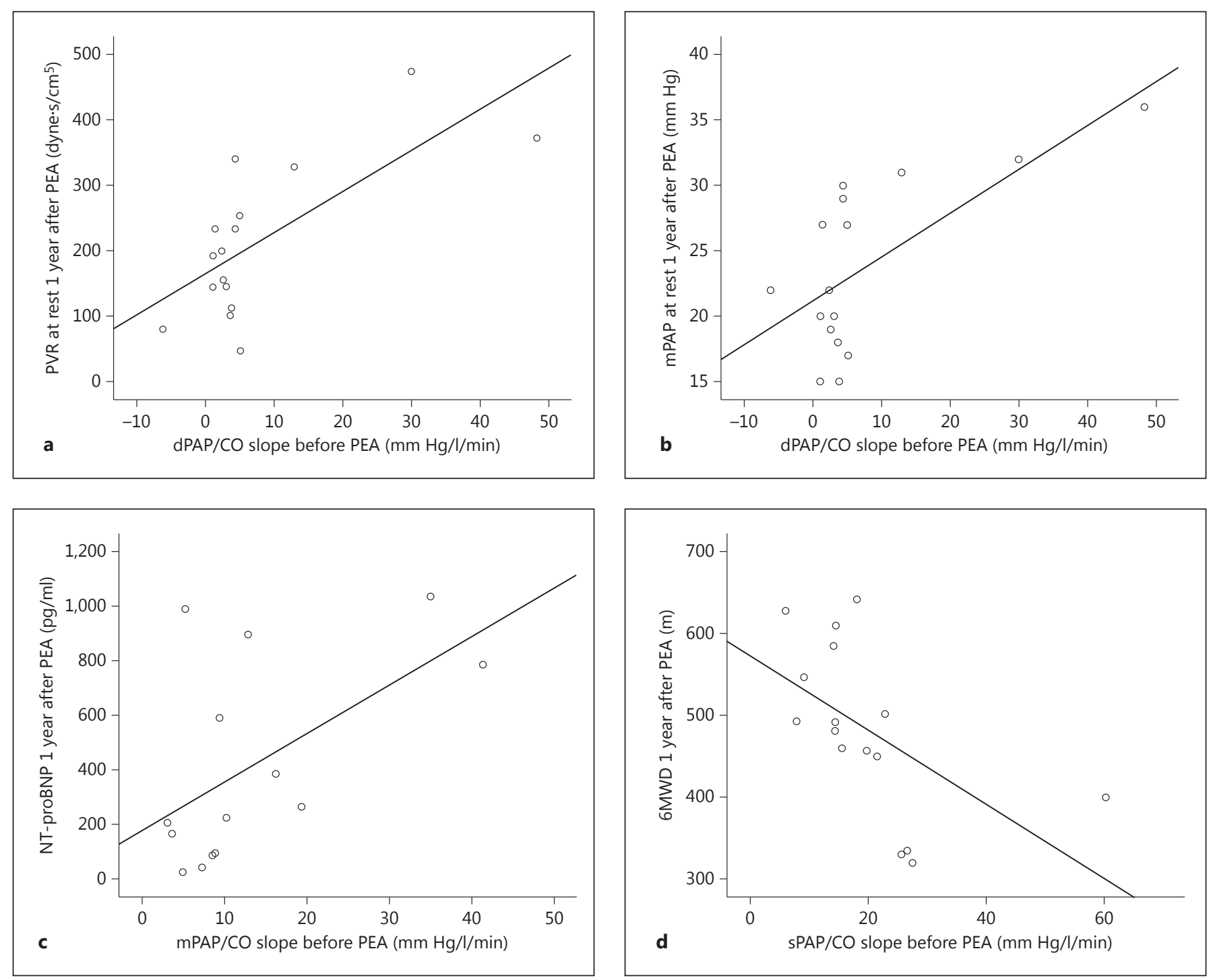

Fig. 3. Associations between the dPAP/CO slope before PEA and PVR at rest after PEA (a), between the dPAP/ CO slope before PEA and mPAP at rest after PEA (b), between the mPAP/CO slope before PEA and NT-proBNP after PEA (c), and between the sPAP/CO slope before PEA and 6MWD after PEA (d).

with persistent high afterload of the RV are contributing to altered pulmonary hemodynamics after PEA [20]. It has been postulated that the outcome of PEA depends on the relationship of small-vessel arteriopathy contributing to CTEPH and the capacity of the small vessels to dilate [16]. In this regard, one can speculate that the relationship between PVR and Cpa was reduced in CTEPH before PEA in our cohort and partly remained impaired after PEA, probably due to persistent structural changes of distal vessels after the removal of proximal obstructions [15].
Physiologically, the pulmonary vessels are a high-flow, low-resistance system, which results in flat $\mathrm{mPAP} / \mathrm{CO}$ slopes during exercise [22]. The extent of small-vessel arteriopathy and the limited potential to vasodilate and/or recruit previously nonperfused vascular areas during increased CO may be reflected by steep pressure-flow slopes, as was shown in heterogeneous groups of PAH patients [22-24]. Thus, hemodynamic measurements that may detect the extent of small-vessel disease may improve the prediction of outcome after PEA. 
Moreover, current data suggested that exercise measurements might be stronger predictors of outcome than resting pulmonary hemodynamics in PAH $[19,21,41$, 42]. In a recent study, it has been shown that Cpa during exercise correlated with peak $\mathrm{VO}_{2}$ in surgically treated CTEPH patients and was a strong predictor of limited exercise capacity after PEA [20].

Our study is in line with these findings, demonstrating improvements of hemodynamic parameters after PEA at rest, as well as a flattened slope of pressure-flow curves during exercise, indicating an increased capacity of the pulmonary vasculature for a higher cardiac output. Furthermore, the flattening of pressure-flow slopes after PEA was numerically even more enhanced in nonresidual $\mathrm{PH}$. Particularly, the slopes of DPG/CO and dPAP/CO decreased and were significantly associated with the hemodynamic outcome after PEA as well as the sPAP/CO slope with $6 \mathrm{MWD}$ and $\mathrm{mPAP} / \mathrm{CO}$ with NT-proBNP. In this context, the diastolic parameters may correlate better with the hemodynamic outcome than $\mathrm{SPAP} / \mathrm{CO}, \mathrm{mPAP} /$ $\mathrm{CO}$ and TPG/CO as they are less influenced by the CO and overall fluid load. Recently, the RV contractile reserve in $\mathrm{PH}$ has been defined by the ability of the RV to eject a large stroke volume despite high pressures and served as a prognostic factor [43], while Cpa was defined as the ratio of stroke volume to pulse pressure also with prognostic significance in CTEPH $[2,20]$. The flattening of pressure-flow slopes after PEA are reflecting both, an enhanced Cpa and RV contractile reserve after PEA. However, a further discrimination of $\mathrm{Cpa}$ and RV contractile reserve by hemodynamic slopes cannot be drawn from our data as both are reflected by an increase in $\mathrm{CO}$. However, the DPG is probably less sensitive to changes in Cpa [44], and therefore, the flattened DPG/CO and $\mathrm{dPAP} / \mathrm{CO}$ slopes are probably more indicative of an enhanced RV contractile reserve after PEA.

In a different study, the DPG was strongly associated with pulmonary vascular remodeling in left-sided heart disease [45] and, therefore, our findings may indicate a substantial increase in pulmonary vascular compliance in our patients, while the resting DPG after PEA was almost reaching a normal range. Along these lines, in patients with chronic left heart failure, the response of mPAP, TPG and PVR to exercise was better related to outcome than resting hemodynamic measurements [46, 47], underlining that the compensatory capacity of the right ventricular pulmonary vascular system is influencing disease progression.

Interestingly, the PAWP/CO slope in our cohort before and after PEA was comparable to previously pub- lished data from patients with left ventricular systolic dysfunction (3.9 mm Hg/l/min) [47]. Moreover, PAWP was increasing during exercise after PEA, which can be interpreted both as a physiological response to the increased CO but partially also as a response unmasking previously unknown left ventricular diastolic dysfunction. With the latter in mind, it is interesting to observe PAWP values $>20 \mathrm{~mm} \mathrm{Hg}$ throughout exercise in elderly subjects [23, 48]. Nevertheless, we conclude that our patients mainly exhibited precapillary PH as (1) the steep TPG/CO slope of our patients before PEA was reflecting a disproportionate increase in mPAP during exercise and (2) mean DPG at baseline was $>5 \mathrm{~mm} \mathrm{Hg}$ indicating a predominantly precapillary $\mathrm{PH}$ [44].

As reported previously, the surgical CTEPH type is significantly associated with the frequency of $\mathrm{PH}$ after PEA $[18,27]$. We did not observe significant differences in hemodynamic slopes or in the frequency of $\mathrm{PH}$ after PEA with regard to the Jamieson type, while the study group consisted mainly of Jamieson type II/III patients. Our study did not include systematic postsurgical imaging with angiography to assess the quantification and differentiation of the proportion of postsurgical perfusion impairment due to nonremovable material and/or secondary microvascular disease. However, our finding that presurgical slopes are correlated with the degree of postsurgical residual $\mathrm{PH}$ possibly reflects the combination of the above. A larger sample size with the inclusion of Jamieson types I and IV are warranted. However, one can speculate that patients with Jamieson type IV 1 year after PEA will provide steeper hemodynamic slopes in case of concomitant $\mathrm{PH}$ after PEA due to enhanced small-vessel pulmonary arteriopathy and impaired Cpa.

Limitations of the study are the small sample size and retrospective analysis of the selected patient population in a single-center study; furthermore, the pathophysiological findings of our study remain to be elucidated in larger prospective trials potentially combined with postprocedural angiographies for the quantification of residual perfusion impairments. Additionally, the sample size limited the statistical analysis; a multivariate regression analysis was not performed. As we are a national referral center, baseline RHC was often performed in the referring hospital, and therefore, these patients could not be included in our analysis. The 1-year follow-up visit was also not mandatory in our center. The investigator who performed the RHC was not blinded to the patient's data and the rate of residual $\mathrm{PH}$ after PEA was slightly higher than reported in the literature; therefore, a selection bias is possible. 
In conclusion, this is the first study to evaluate the pulmonary hemodynamic profile during submaximal exercise in CTEPH. Our preliminary results indicate that in CTEPH the pulmonary response to exercise before PEA was more closely related to the hemodynamic outcome 1 year after PEA than to measurements at rest. The flattening of pressure-flow slopes after PEA reflects the enhanced capacity of the right ventricular pulmonary vascular system in response to increased CO. For the evalu- ation of pressure-flow slopes as an independent predictor of outcome after PEA, future studies in larger patient groups are warranted.

\section{Financial Disclosure and Conflicts of Interest}

All authors have reported that no potential conflicts of interest exist with any companies/organizations whose products or services may be discussed in this article.

\section{References}

1 Kim NH, Delcroix M, Jenkins DP, Channick R, Dartevelle P, Jansa P, Lang I, Madani MM, Ogino H, Pengo V, Mayer E: Chronic thromboembolic pulmonary hypertension. J Am Coll Cardiol 2013;62(suppl 25):D92D99.

2 Delcroix M, Vonk Noordegraaf A, Fadel E, Lang I, Simonneau G, Naeije R: Vascular and right ventricular remodelling in chronic thromboembolic pulmonary hypertension. Eur Respir J 2013;41:224-232.

3 Vonk-Noordegraaf A, Haddad F, Chin KM, Forfia PR, Kawut SM, Lumens J, Naeije R, Newman J, Oudiz RJ, Provencher S, Torbicki A, Voelkel NF, Hassoun PM: Right heart adaptation to pulmonary arterial hypertension: physiology and pathobiology. J Am Coll Cardiol 2013;62(suppl 25):D22D33.

4 Lang IM, Pesavento R, Bonderman D, Yuan JX: Risk factors and basic mechanisms of chronic thromboembolic pulmonary hypertension: a current understanding. Eur Respir J 2013;41:462-468.

5 Bogaard HJ, Abe K, Vonk Noordegraaf A, Voelkel NF: The right ventricle under pressure: cellular and molecular mechanisms of right-heart failure in pulmonary hypertension. Chest 2009;135:794-804.

6 Freed DH, Thomson BM, Tsui SS, Dunning JJ, Sheares KK, Pepke-Zaba J, Jenkins DP: Functional and haemodynamic outcome 1 year after pulmonary thromboendarterectomy. Eur J Cardiothorac Surg 2008;34:525529; discussion 529-530.

7 Archibald CJ, Auger WR, Fedullo PF, Channick RN, Kerr KM, Jamieson SW, Kapelanski DP, Watt CN, Moser KM: Long-term outcome after pulmonary thromboendarterectomy. Am J Respir Crit Care Med 1999;160: 523-528.

8 D’Armini AM, Zanotti G, Ghio S, Magrini G, Pozzi M, Scelsi L, Meloni G, Klersy C, Vigano M: Reverse right ventricular remodeling after pulmonary endarterectomy. J Thorac Cardiovasc Surg 2007;133:162-168.
9 Corsico AG, D’Armini AM, Cerveri I, Klersy C, Ansaldo E, Niniano R, Gatto E, Monterosso C, Morsolini M, Nicolardi S, Tramontin C, Pozzi E, Vigano M: Long-term outcome after pulmonary endarterectomy. Am J Respir Crit Care Med 2008;178:419424.

10 Saouti N, Morshuis WJ, Heijmen RH, Snijder RJ: Long-term outcome after pulmonary endarterectomy for chronic thromboembolic pulmonary hypertension: a single institution experience. Eur J Cardiothorac Surg 2009;35: 947-952; discussion 952.

11 Ishida K, Masuda M, Tanabe N, Matsumiya G, Tatsumi K, Nakajima N: Long-term outcome after pulmonary endarterectomy for chronic thromboembolic pulmonary hypertension. J Thorac Cardiovasc Surg 2012;144: 321-326.

12 Freed DH, Thomson BM, Berman M, Tsui SS, Dunning J, Sheares KK, Pepke-Zaba J, Jenkins DP: Survival after pulmonary thromboendarterectomy: effect of residual pulmonary hypertension. J Thorac Cardiovasc Surg 2011; 141:383-387.

13 Kunihara T, Gerdts J, Groesdonk H, Sata F, Langer F, Tscholl D, Aicher D, Schafers HJ: Predictors of postoperative outcome after pulmonary endarterectomy from a 14-year experience with 279 patients. Eur J Cardiothorac Surg 2011;40:154-161.

14 Kunihara T, Moller M, Langer F, Sata F, Tscholl D, Aicher D, Schafers HJ: Angiographic predictors of hemodynamic improvement after pulmonary endarterectomy. Ann Thorac Surg 2010;90:957-964; discussion 964.

15 MacKenzie Ross RV, Toshner MR, Soon E, Naeije R, Pepke-Zaba J: Decreased time constant of the pulmonary circulation in chronic thromboembolic pulmonary hypertension. Am J Physiol Heart Circ Physiol 2013; 305:H259-H264.

16 Grignola JC, Domingo E: Pulmonary endarterectomy in chronic thromboembolic pulmonary hypertension: how can patients be better selected? World J Cardiol 2013;5:1821.
17 Hardziyenka M, Reesink HJ, Bouma BJ, de Bruin-Bon HA, Campian ME, Tanck MW, van den Brink RB, Kloek JJ, Tan HL, Bresser $P$ : A novel echocardiographic predictor of inhospital mortality and mid-term haemodynamic improvement after pulmonary endarterectomy for chronic thrombo-embolic pulmonary hypertension. Eur Heart J 2007;28: 842-849.

18 Skoro-Sajer N, Hack N, Sadushi-Kolici R, Bonderman D, Jakowitsch J, Klepetko W, Hoda MA, Kneussl MP, Fedullo P, Lang IM: Pulmonary vascular reactivity and prognosis in patients with chronic thromboembolic pulmonary hypertension: a pilot study. Circulation 2009;119:298-305.

19 Chaouat A, Sitbon O, Mercy M, Poncot-Mongars R, Provencher S, Guillaumot A, Gomez E, Selton-Suty C, Malvestio P, Regent D, Paris $C$, Herve P, Chabot F: Prognostic value of exercise pulmonary haemodynamics in pulmonary arterial hypertension. Eur Respir J 2014;44:704-713.

20 Bonderman D, Martischnig AM, Vonbank K, Nikfardjam M, Meyer B, Heinz G, Klepetko W, Naeije R, Lang IM: Right ventricular load at exercise is a cause of persistent exercise limitation in patients with normal resting pulmonary vascular resistance after pulmonary endarterectomy. Chest 2011;139:122127.

21 Blumberg FC, Arzt M, Lange T, Schroll S, Pfeifer M, Wensel R: Impact of right ventricular reserve on exercise capacity and survival in patients with pulmonary hypertension. Eur J Heart Fail 2013;15:771-775.

22 Lewis GD, Bossone E, Naeije R, Grunig E, Saggar R, Lancellotti P, Ghio S, Varga J, Rajagopalan S, Oudiz R, Rubenfire M: Pulmonary vascular hemodynamic response to exercise in cardiopulmonary diseases. Circulation 2013;128:1470-1479.

23 Janicki JS, Weber KT, Likoff MJ, Fishman AP: The pressure-flow response of the pulmonary circulation in patients with heart failure and pulmonary vascular disease. Circulation 1985;72:1270-1278. 
24 Blumberg FC, Riegger GA, Pfeifer M: Hemodynamic effects of aerosolized iloprost in pulmonary hypertension at rest and during exercise. Chest 2002;121:1566-1571.

25 Task Force for Diagnosis and Treatment of Pulmonary Hypertension of European Society of Cardiology (ESC); European Respiratory Society (ERS); International Society of Heart and Lung Transplantation (ISHLT); Galie N, Hoeper MM, Humbert M, Torbicki A, Vachiery JL, Barbera JA, Beghetti M, Corris P, Gaine S, Gibbs JS, Gomez-Sanchez MA, Jondeau G, Klepetko W, Opitz C, Peacock A, Rubin L, Zellweger M, Simonneau G: Guidelines for the diagnosis and treatment of pulmonary hypertension. Eur Respir J 2009;34: 1219-1263.

26 Mayer E: Surgical and post-operative treatment of chronic thromboembolic pulmonary hypertension. Eur Respir Rev 2010;19:64-67.

27 Thistlethwaite PA, Mo M, Madani MM, Deutsch R, Blanchard D, Kapelanski DP, Jamieson SW: Operative classification of thromboembolic disease determines outcome after pulmonary endarterectomy. J Thorac Cardiovasc Surg 2002;124:1203-1211.

28 Kovacs G, Avian A, Tscherner M, Foris V, Bachmaier G, Olschewski A, Olschewski H: Characterization of patients with borderline pulmonary arterial pressure. Chest 2014;146: 1486-1493.

29 Kovacs G, Avian A, Pienn M, Naeije R, Olschewski $\mathrm{H}$ : Reading pulmonary vascular pressure tracings. How to handle the problems of zero leveling and respiratory swings. Am J Respir Crit Care Med 2014;190:252257.

30 Hilde JM, Skjorten I, Hansteen V, Melsom MN, Hisdal J, Humerfelt S, Steine K: Haemodynamic responses to exercise in patients with COPD. Eur Respir J 2013;41:1031-1041.

31 Balady GJ, Arena R, Sietsema K, Myers J, Coke L, Fletcher GF, Forman D, Franklin B, Guazzi M, Gulati M, Keteyian SJ, Lavie CJ, Macko R, Mancini D, Milani RV; American Heart Association Exercise, Cardiac Rehabilitation, and Prevention Committee of the Council on Clinical Cardiology; Council on Epidemiology and Prevention; Council on Peripheral Vascular Disease; Interdisciplinary Council on Quality of Care and Outcomes Research: Clinician's Guide to cardiopulmonary exercise testing in adults: a scientific statement from the American Heart Association. Circulation 2010;122:191-225.
32 ATS Committee on Proficiency Standards for Clinical Pulmonary Function Laboratories: ATS statement: guidelines for the six-minute walk test. Am J Respir Crit Care Med 2002; 166:111-117.

33 Rudski LG, Lai WW, Afilalo J, Hua L, Handschumacher MD, Chandrasekaran K, Solomon SD, Louie EK, Schiller NB: Guidelines for the echocardiographic assessment of the right heart in adults: a report from the American Society of Echocardiography endorsed by the European Association of Echocardiography, a registered branch of the European Society of Cardiology, and the Canadian Society of Echocardiography. J Am Soc Echocardiogr 2010;23: 685-713; quiz 786-688.

34 van der Plas MN, Reesink HJ, Roos CM, van Steenwijk RP, Kloek JJ, Bresser P: Pulmonary endarterectomy improves dyspnea by the relief of dead space ventilation. Ann Thorac Surg 2010;89:347-352.

35 Sato M, Ando M, Kaneko K, Higuchi Y, Kondo H, Akita K, Ishida M, Takagi Y: Respiratory and hemodynamic changes in patients with chronic thromboembolic pulmonary hypertension 1 year after pulmonary endarterectomy. Ann Vasc Dis 2013;6:578-582.

36 Pepke-Zaba J, Delcroix M, Lang I, Mayer E, Jansa P, Ambroz D, Treacy C, D'Armini AM, Morsolini M, Snijder R, Bresser P, Torbicki A, Kristensen B, Lewczuk J, Simkova I, Barbera JA, de Perrot M, Hoeper MM, Gaine S, Speich R, Gomez-Sanchez MA, Kovacs G, Hamid AM, Jais X, Simonneau G: Chronic thromboembolic pulmonary hypertension (CTEPH): results from an international prospective registry. Circulation 2011;124:1973-1981.

37 Mauritz GJ, Vonk-Noordegraaf A, Kind T, Surie S, Kloek JJ, Bresser P, Saouti N, Bosboom J, Westerhof N, Marcus JT: Pulmonary endarterectomy normalizes interventricular dyssynchrony and right ventricular systolic wall stress. J Cardiovasc Magn Reson 2012;14: 5.

38 Bresser P, Pepke-Zaba J, Jais X, Humbert M, Hoeper MM: Medical therapies for chronic thromboembolic pulmonary hypertension: an evolving treatment paradigm. Proc Am Thorac Soc 2006;3:594-600.

39 Rahnavardi M, Yan TD, Cao C, Vallely MP, Bannon PG, Wilson MK: Pulmonary thromboendarterectomy for chronic thromboembolic pulmonary hypertension: a systematic review. Ann Thorac Cardiovasc Surg 2011;17: 435-445.
40 Surie S, van der Plas MN, Marcus JT, Kind T, Kloek JJ, Vonk-Noordegraaf A, Bresser P: Effect of Pulmonary Endarterectomy for Chronic Thromboembolic Pulmonary Hypertension on Stroke Volume Response to Exercise. Am J Cardiol 2014;114:136-140.

41 Nickel N, Golpon H, Greer M, Knudsen L, Olsson K, Westerkamp V, Welte T, Hoeper MM: The prognostic impact of follow-up assessments in patients with idiopathic pulmonary arterial hypertension. Eur Respir J 2012; 39:589-596.

42 van de Veerdonk MC, Kind T, Marcus JT, Mauritz GJ, Heymans MW, Bogaard HJ, Boonstra A, Marques KM, Westerhof N, Vonk-Noordegraaf A: Progressive right ventricular dysfunction in patients with pulmonary arterial hypertension responding to therapy. J Am Coll Cardiol 2011;58:25112519.

43 Grunig E, Tiede H, Enyimayew EO, Ehlken N, Seyfarth HJ, Bossone E, D'Andrea A, Naeije R, Olschewski H, Ulrich S, Nagel C, Halank $\mathrm{M}$, Fischer C: Assessment and prognostic relevance of right ventricular contractile reserve in patients with severe pulmonary hypertension. Circulation 2013;128:2005-2015.

44 Naeije R, Vachiery JL, Yerly P, Vanderpool R: The transpulmonary pressure gradient for the diagnosis of pulmonary vascular disease. Eur Respir J 2013;41:217-223.

45 Gerges C, Gerges M, Lang MB, Zhang Y, Jakowitsch J, Probst P, Maurer G, Lang IM: Diastolic pulmonary vascular pressure gradient: a predictor of prognosis in 'out-of-proportion' pulmonary hypertension. Chest 2013; 143:758-766.

46 Ghio S, Gavazzi A, Campana C, Inserra C, Klersy C, Sebastiani R, Arbustini E, Recusani F, Tavazzi L: Independent and additive prognostic value of right ventricular systolic function and pulmonary artery pressure in patients with chronic heart failure. J Am Coll Cardiol 2001;37:183-188.

47 Lewis GD, Murphy RM, Shah RV, Pappagianopoulos PP, Malhotra R, Bloch KD, Systrom DM, Semigran MJ: Pulmonary vascular response patterns during exercise in left ventricular systolic dysfunction predict exercise capacity and outcomes. Circ Heart Fail 2011; 4:276-285.

48 Reeves JT, Groves BM, Cymerman A, Sutton JR, Wagner PD, Turkevich D, Houston CS: Operation Everest II: cardiac filling pressures during cycle exercise at sea level. Respir Physiol 1990;80:147-154. 